\title{
Antipatrimonio y turismo oscuro. El público escolar
}

Jesús Estepa Giménez y Myriam Martín Cáceres | Dpto. de Didácticas Integradas, Universidad de Huelva

URL de la contribución <www.iaph.es/revistaph/index.php/revistaph/article/view/5082>

La educación patrimonial tradicionalmente se ha considerado desde la perspectiva del empleo del patrimonio como recurso educativo para la enseñanza/aprendizaje de la Historia y la Historia del Arte, fundamentalmente, o como recurso turístico, en la línea de desarrollar la economía de determinadas zonas con un reconocido potencial patrimonial, prioritariamente también de carácter histórico-artístico. Estos dos contextos no son excluyentes, sino complementarios y desde una perspectiva didáctica actual, incluso los aprendizajes informales, basados en la experiencia y observación del medio socionatural -para nosotros incluye también el patrimonio natural, etnológico y científico-tecnológico-, son más significativos y funcionales que los adquiridos en la escuela. La potencialidad didáctica de este aprendizaje vivencial es la que convierte a los estudiantes en uno de los tipos de público del turismo y al turismo escolar en una línea de investigación didáctica, como se puso de manifiesto en el Primer Simposio Internacional de Turismo Educativo; el Turismo Escolar, celebrado en Barcelona en 2011. De ahí que consideremos que esta perspectiva didáctica puede ser de interés en este debate sobre el turismo oscuro.

Consideramos que este tipo de turismo está muy vinculado a espacios de memoria traumática, que no tiene por qué simbolizar lo mismo para todas las personas, por lo que es de naturaleza polémica, y por ende, una temática controvertida. En correspondencia con estas memorias en conflicto, aunque también por otro tipo de controversias, hemos acuñado el término de patrimonios controversiales. Con este concepto, queremos incidir en la selección de elementos patrimoniales no por sus valores estéticos o medioambientales, sino en atención a diversas causas que suscitan conflicto, ya sean de carácter ideológico, político, económico, medioam- biental o por interacción entre ellos (Estepa-Giménez y Martín-Cáceres 2018).

Como ya indicamos en una aportación para otro debate de revista PH (Estepa-Giménez 2019), al centrar la atención en estos elementos patrimoniales controvertidos pretendemos el desarrollo del pensamiento crítico y argumentativo entre el alumnado -muy necesario para la alfabetización científica de la ciudadanía- a través del análisis, del contraste de opiniones e informaciones, del debate y de la argumentación sobre estos bienes patrimoniales. De los ocho tipos de patrimonio controversiales que distinguimos (Estepa, Cuenca y Martín Cáceres 2021), nos centramos exclusivamente en el que hemos denominado antipatrimonio, por los contravalores que representa, con el que pretendemos mantener la memoria o sacar del olvido interesado las recientes atrocidades de las guerras, persecuciones y represiones cometidas por el género humano. Es precisamente el concepto de antipatrimonio el que relacionamos con el turismo oscuro, aunque nosotros lo trabajamos principalmente en contextos educativos formales (Estepa y Delgado-Algarra 2020).

Como hemos señalado en un publicación previa (EstepaGiménez y Martín Cáceres 2020), la postulación que se realiza es que estos espacios deben contribuir a que la ciudadanía se haga preguntas y reflexione sobre las acciones acontecidas en detrimento y contra la humanidad como especie, aunque estos postulados no sean compartidos por todos, ya que llevan implícitos, en ocasiones, un conflicto de memorias.

Este nuevo enfoque que estamos investigando para la enseñanza del antipatrimonio es necesario que se refuerce y complemente en las visitas del turismo esco- 


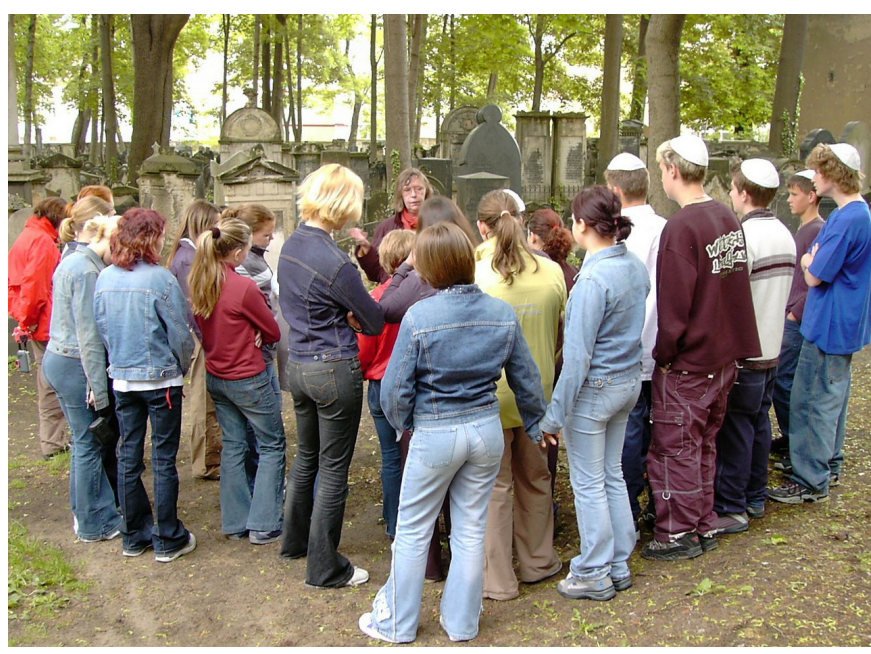

Escolares en un cementerio judío en Dresde | foto Pixabay

lar, que como variante del turismo cultural, debe pretender no solo entretener sino también educar. La musealización de estos lugares debe presentarlos, por tanto, con el fin de ejemplificar la importancia de establecer la paz y la comprensión entre personas y países. En un principio, se puede afirmar que en todos estos espacios se destacan las consecuencias negativas de las guerras acompañando el discurso con la defensa de la tolerancia y la paz, aunque estudios posteriores ponen de manifiesto que la interpretación que se lleva a cabo en estos sitios acaba dejando en un segundo plano estas ideas para prevalecer el enfoque heroico o nacionalista. Podríamos señalar como ejemplo del primer caso el Anne Frank House en Ámsterdam o para el segundo caso el Museum of Tolerance (MOT) de Los Ángeles, donde se atiende más a lo sensacionalista y al reclamo turístico.

En los espacios de este nuevo turismo, por el contrario, debe ofrecerse a los grupos escolares material didáctico, en coordinación con los centros escolares, que facilite la comprensión, interpretación, empatía y controversia en relación con la discriminación, humillación, pena, perdón, olvido, memoria y para el establecimiento de vínculos emocionales con los soldados o las víctimas discriminadas, torturadas, asesinadas, represaliadas, marginadas o exiliadas.
En definitiva, desde nuestra perspectiva, si la reflexión sobre el turismo oscuro y el patrimonio traumático no ha hecho más que empezar, es necesario que incorpore este enfoque didáctico controvertido de cara a educar no solo a los escolares, sino al público visitante en general en los valores propios de una ciudadanía no violenta, crítica y democrática.

\section{BIBLIOGRAFÍA}

- Estepa-Giménez, J. (2019) Memoria, patrimonio y ciudadanía: una contribución desde una perspectiva didáctica. Revista PH, n. ${ }^{\circ}$ 96, pp-225-226. Disponible en: https://www. iaph.es/revistaph/index.php/revistaph/article/view/4299 [Consulta: 15/12/2021]

- Estepa-Giménez, J. y Delgado-Algarra, E. (2020) Construyendo un compromiso democrático: memoria histórica, patrimonio y educación ciudadana. En: Sáez-Rosenkranz, I. y Prats Cuevas, J. (ed.) Memoria histórica y enseñanza de la Historia. Gijón: Trea, pp. 45-64

- Estepa-Giménez, J. y Martín-Cáceres, M.J. (2018) Competencia en conciencia y expresiones culturales y educación histórica. Patrimonios en conflicto y pensamiento crítico. En: Gómez Carrasco, C.J. y Miralles, P. (coord.) La educación histórica ante el reto de las competencias. Métodos, recursos y enfoques de enseñanza. Barcelona: Octaedro, pp. 75-86

- Estepa-Giménez, J. y Martín-Cáceres, M.J. (2020) Heritage in Conflict: A way to educate in a critical and participative citizenship. En: Delgado, E. y Cuenca, J.M. (coord.) Handbook of Research on Citizenship and Heritage Education. Hershey: igi Global, pp. 43-55

- Estepa-Giménez, J.; Cuenca López, J.M. y Martín Cáceres, M.J. (2021) Líneas futuras de trabajo desde el proyecto Epitec: patrimonios controversiales para una educación ecosocial de la ciudadanía. En: Cuenca López, J. M., Estepa Giménez, J. y Martín Cáceres, M. Investigación y buenas prácticas en educación patrimonial entre la escuela y el museo. Territorio, emociones y ciudadanía. Gijón: Trea, pp. 485-496 